\title{
ERRATUM
}

Á. Rocino $\cdot$ R. de Biasi

\section{Very high purity FVIII issues - Hemofil-M study}

Ann Hematol Supplement III to Volume 68 (1994) pp. S55-S57

In the above paper the following acknowledgement should have been published:

Acknowledgements This work was supported by Regione Campania grant $n^{\circ} 3290$ of 29. 5. 1990.

A. Rocino $\cdot$ R. de Biasi

Dipartimento di Ematologia,

Centro Emofilia e Trombosi,

Ospedale "Nuovo Pellegrini",

Via Briganti, 255,

I-80144 Napoli, Italy 